University of Nebraska - Lincoln

DigitalCommons@University of Nebraska - Lincoln

Civil and Environmental Engineering Faculty

Publications

Civil and Environmental Engineering

$8-2020$

\title{
Life Cycle Assessment of the US Beef Processing through Integrated Hybrid Approach
}

Shaobin Li

Yuwei Qin

Jeyamkondan Subbiah

Bruce Dvorak

Follow this and additional works at: https://digitalcommons.unl.edu/civilengfacpub

Part of the Beef Science Commons, Environmental Engineering Commons, and the Food Processing Commons

This Article is brought to you for free and open access by the Civil and Environmental Engineering at DigitalCommons@University of Nebraska - Lincoln. It has been accepted for inclusion in Civil and Environmental Engineering Faculty Publications by an authorized administrator of DigitalCommons@University of Nebraska Lincoln. 


\title{
Life Cycle Assessment of the US Beef Processing through Integrated Hybrid Approach
}

\author{
Shaobin Li, ${ }^{1}$ Yuwei Qin, ${ }^{2}$ Jeyamkondan Subbiah, ${ }^{3}$ and Bruce Dvorak ${ }^{4}$
}

1. Department of Civil and Environmental Engineering, University of Illinois at Urbana-Champaign, Urbana, Illinois, USA

2. Department of Civil and Environmental Engineering, University of California, Berkeley, California, USA

3. Department of Food Science, University of Arkansas, Fayetteville, Arkansas, USA

4. Department of Civil and Environmental Engineering, University of Nebraska-Lincoln, Lincoln, Nebraska, USA

Corresponding author - Shaobin Li, Department of Civil and Environmental Engineering, University of Illinois at Urbana-Champaign, 3144 Newmark Civil Engineering Laboratory, 205 N. Mathews Ave., Urbana, IL, 61801, USA; email shaobin@illinois.edu

\begin{abstract}
Hybrid life cycle assessment (LCA) incorporating process-based and economic input-output (EIO)based inventory data has been applied in various industries (e.g., wind energy, biofuel). Few hybrid LCA studies have been found in the food industry. This work analyzes the life cycle environmental impacts of the US beef processing industry using process-based and integrated hybrid LCA. The process-based inventory includes all resource inputs and waste outputs associated with a beef processing plant. The EIO-based inventory includes key activities missing in the process-based inventory, such as technical and management service, wood and paper, and industrial equipment. Ten environmental impact categories from TRACI v2.1 and one aggregated environmental single score are considered. The results show that environmental impact from EIO-based inventory contributes a meaningful fraction of the impact for ozone depletion $(67 \%)$, respiratory effects (42\%), fossil fuel depletion (38\%), and smog (28\%) (as opposed to process-based inventory). These results emphasize the relative potential for the US beef processing industry of greening the supply chain (e.g., technical and management services, industrial equipment) to reduce environmental impacts. Furthermore, we perform uncertainty and global sensitivity analysis for key parameters of all environmental
\end{abstract}


categories. The uncertainty analysis showed that the environmental impacts contributed by the EIO system can range from $7 \%$ to $15 \%$ under Monte Carlo simulations (10,000 runs) when representing the impacts using an aggregated environmental single score. The global sensitivity analysis using the Sobol method for all environmental categories shows that the electricity, natural gas, and wastewater treatment from the process system and beef price from the EIO system are the four most sensitive parameters to all ten TRACI environmental categories and the environmental single score.

Keywords: beef processing, hybrid life cycle assessment, global sensitivity analysis

\section{Introduction}

Global meat production is expected to increase twofold by 2050 to meet the demand of increased world population and increased prosperity especially in the developing countries that have lower meat intake due to their current economic development compared to meat consumption in the global average diet (Charles et al., 2018; Steinfeld et al., 2006). Among various meat products, beef products have been reported to have the highest environmental footprints, such as greenhouse gas (GHG), water, fossil energy, and eutrophication (Eshel et al., 2014; Roy et al., 2009; Ziara et al., 2016). Specifically, Eshel et al. (2014) compared environmental life cycle impacts of eggs, dairy, and different meat products (i.e., beef, poultry, pork) and found that GHG emissions from beef meat is $10.0 \mathrm{~kg} \mathrm{CO}$-eq per 1000 kcals while GHG emissions from other meat products range roughly between 1.5 and $2.0 \mathrm{~kg} \mathrm{CO}$-eq per $1000 \mathrm{kcals}$. Although many studies have shown that the majority of the environmental life cycle impacts of meat products is in the farm stage (Asem-Hiablie et al., 2019; Mogensen et al., 2016), there is still significant room for improvements in the stage of meat processing (including slaughter, fabrication, packaging, and on- and off-site waste treatment). The beef processing industry in the US is highly centralized with four big corporations producing $80 \%$ of the beef products (National Cattleman's Beef Association, 2016), while $97 \%$ of 2.1 million farms are primarily family-owned and widely dispersed in the US (USDA NASS, 2015). Thus, effective sustainability improvements may be easier to implement at the beef processing stage than at the farm stage.

With the expected growing demand for meat products, the sustainability of beef products is of increased concern to meat processing industries and consumers (Charles et al., 2018). US beef is expected to play an important role in the global meat supply chain. By January 2020, US beef production accounted for $20.3 \%$ of the world's beef production and $12.9 \%$ of the world's beef export, ranking the US as the third country in terms of the amount of beef export (USDA FAS, 2020). Therefore, advancing the sustainability of US beef slaughtering is an important need. Industrial stakeholders in the US meat processing industry have initiated sustainability programs and activities to advance the sustainability of their products (e.g., JBS Beef, 2019; Smithfield Foods, 2019; Tyson Foods, 2017). Those sustainability initiatives developed by industrial stakeholders not only help reduce the environmental footprints of their products and promote cleaner production but also enhance their brand images.

Life cycle assessment (LCA) is a well-established technique for quantifying the overall environmental impacts of a product or system and has been widely applied in various food 
systems (Battagliese et al., 2015; Peters et al., 2010; Silva and Sanjuán, 2019). For example, Battagliese et al. (2015) measured the life cycle environmental and economic impacts of the US beef supply chain from beef production to processing to its consumer stage using ecoefficiency analysis (EEA). However, the study from Battagliese et al. (2015) evaluated only the environmental impacts of beef processing as a whole instead of at the process level, as collecting data from the beef processing facilities is challenging. This is because beef companies are generally conservative about sharing their proprietary data and granting access to collect data onsite. Peters et al. (2010) also reported GHG emissions and energy use of beef production in Australia by dividing it into three stages: farm, feedlot, and processing. However, the process-level assessment is also missing, thus limiting the applications of effective measures for cleaner beef production. There is an important need to investigate the environmental impacts of beef processing more granularly, thus providing more useful information on the potential mitigation of environmental footprints related to the beef slaughtering process.

LCA can generally be classified into three categories depending on different methods of inventory data collection, i.e., process based, economic input-output (EIO)-based, and hybrid LCA (Crawford et al., 2018; Suh and Huppes, 2005; Yu and Wiedmann, 2018). Processbased LCA applies a bottom-up approach to collect inventory data of interest, while the EIO-based LCA employs a top-down approach to estimate inventory data and environmental emissions from a wide range of economic activities. The process-based approach can yield more accurate inventory data than the inventory data estimated from the EIObased approach. However, process-based inventory usually results in system truncations because it is difficult to collect inventory data on all inputs (e.g., technical and financial services) at the process level.

The EIO-based approach estimates inventory data at a coarser resolution, typically based on available EIO databases aggregating specific industries into a general sector. For example, specific meat processing industries (e.g., beef, pork, and lamb) are aggregated into the red meat sector in the environmentally extended input-output model of the United States (USEEIO) database developed by US Environmental Protection Agency (EPA) based on an IO table compiled by the US Bureau of Economic Analysis (Yang et al., 2017). The advantage of EIO-based LCA is its ability to fully capture inventory data of environmental emissions via transaction across industries, thus avoiding system truncation issues compared to traditional process-based LCA. For example, most process-based LCAs do not account for the environmental impacts embedded in a wide variety of services (e.g., financial, governmental services) when manufacturing a product because of data limitations. Examples of financial services include economic activities of insurance and monetary authorities, while governmental services include activities and regulations associated with federal and state governments.

The hybrid LCA can be considered as a combination of process-based LCA and EIObased LCA. The hybrid LCA can be further divided into three approaches, including tiered hybrid, EIO-based hybrid, and integrated hybrid LCA (Suh and Huppes, 2005). It is believed that a hybrid LCA can quantify the environmental impacts more comprehensively compared to process-based or EIO-based by complementing system boundary truncation in a process-based approach with the EIO database. In this regard, available process-based 
inventory data are used under the assumption that process-based inventory data are more accurate than EIO-based inventory data (national, industry averages). More details on the three hybrid approaches are introduced in the following section "Overview of hybrid LCA approaches in the literature."

Most LCA studies on food products apply traditional process-based approaches to collect inventory data (Kim et al., 2013; Li et al., 2018a; Mogensen et al., 2016; Rotz et al., 2019). Integrated hybrid LCAs have been applied in other different systems (e.g., energy) to supplement the truncations of system boundary (Wiedmann et al., 2011; Zhao and You, 2019). However, those integrated hybrid LCAs are mainly focused on one or two environmental indicators (e.g., GHG, fossil fuel footprint), thus limiting our understanding of the wide spectrum of various environmental impacts available in LCA studies, such as eutrophication, human health, and ecotoxicity.

This work hypothesizes that an integrated hybrid life cycle assessment of US beef processing can help identify which environmental impacts are notably increased when including those associated with the embedded economic activities as compared to when only process-based data is used. We first investigated the environmental impacts of US beef processing at the process level using inventory data collected from large, commercial, large-size beef-processing facilities located in the Midwest. We then applied integrated hybrid LCA to the environmental impacts of beef processing and compared the results with the results from process-based LCA. To our knowledge, this work is the first attempt to investigate the environmental life cycle impacts of the US beef processing industry at the process level as well as the application of hybrid LCA in meat processing. The framework developed in this work can be widely applied to many other food systems to investigate their environmental footprints and ultimately identify hotspots where major improvements can take place.

\section{Overview of hybrid LCA approaches in the literature}

Hybrid LCA has been loosely referred to as any approach that combines process-based and EIO-based LCA (Suh and Huppes, 2005). Based on different ways of performing inventory compilation, hybrid LCA can be categorized into three types: (1) tiered hybrid LCA, (2) EIO-based hybrid LCA, and (3) integrated hybrid LCA. In this study, we use integrated hybrid LCA, the most comprehensive one among the three hybrid approaches.

For tiered hybrid LCA, process-based inventory includes the use and end-of-life stage and certain upstream processes while EIO-based inventory covers most upstream processes. The results are simply added as the total hybrid LCA. This tiered hybrid LCA method was originally introduced in an energy analysis study that combines process-based and EIO-based data by Bullard et al., in 1978. The boundaries between process-based and EIObased inventory can vary significantly depending on research needs and data availability. For example, process-based inventory can cover the use and end of life of the studied product, while the EIO-based inventory covers the upstream production. It is recommended that extensive process-based inventory data gathering are conducted first, and EIO-based inventory are performed to account for some processes where process data are not available. For example, Bilec et al. (2006) combined process-based inventory (e.g., transportation, 
onsite electricity use, diesel use of construction equipment) and EIO-based inventory (e.g., service sectors) for an LCA study on infrastructure construction process (Bilec et al., 2006). Tiered hybrid analysis can provide a relatively complete and quick analysis. However, since the process-based and EIO-based systems are analyzed separately, the interaction between them cannot be evaluated systematically. The EIO-based hybrid analysis utilizes disaggregated industry sectors or creates new sectors in an augmented IO table. The disaggregated sectors or newly created sectors then apply detailed process-based emission data to evaluate a certain product or service. For example, Wiedmann applied a disaggregated multiregion EIO modeling framework to evaluate wind power in the UK. Since the EIO-based approach partially utilizes the tiered hybrid approach, the process systems and the macroeconomic systems are also not fully integrated.

The last hybrid LCA approach is the integrated hybrid LCA that systematically interconnects the environmental inventory of process-based and economic systems. Based on the assumption that process-specific data are more reliable than EIO data, the inventory of integrated hybrid LCA first utilizes process data, and then the EIO data is integrated by connecting the upstream and downstream wherever process-specific data are not available. For example, in the beef-processing plant, most operational resource inputs and waste outputs are part of the process-specific data. However, the environmental impacts embedded with construction, operation maintenance, and various services in a beef-processing plant and other processes for manufacturing materials are not readily available through process-specific data and can be linked via the upstream and downstream cutoff matrix, instead of being treated independently in tiered hybrid LCA. Most existing studies apply integrated hybrid LCA approach in energy systems and only considered one or two environmental impact categories, such as GHG emissions and energy footprint (Gao and You, 2018; Wiedmann et al., 2011; Yao et al., 2014).

Hybrid LCA approaches have also been applied in the city scale. For example, a study designed a hybrid LCA to quantify the city scale GHG emissions that incorporate emissions from surface and airline travel (process-based) and emissions from essential urban materials, including food, water, energy, and concrete (EIO-based) (Ramaswami et al., 2008). More recently, attempts have been made to couple a dynamic system with hybrid LCA. Zhai and William accounted the energy and carbon emissions of technology-driven dynamics of photovoltaic systems by hybrid LCA (Zhai and Williams, 2010). However, applications of hybrid LCA in food systems are still rare. Peters et al. (2010) evaluated the red meat production in Australia using tiered hybrid LCA approach. To the knowledge of the authors, no studies have applied the integrated hybrid approach in the food processing industry, which calls for a need to bridge the research gap.

\section{Methods}

\subsection{Goal and scope}

The goal of this study is to comprehensively evaluate the environmental impacts for beef processing in the US by applying an integrated hybrid LCA approach. As shown in Figure 1, the system boundary of beef processing considered in this study consists of two systems: a process-based system and an EIO-based system. The process-based part includes typical 
steps in beef-processing facilities and its onsite and offsite waste treatment. A typical beefprocessing facility generally starts from the holding yard, killing floor, chilling room, and fabrication floor, and finally various products are packaged and stored. The killing floor can further be split into key steps, including stunning, bleeding, hide and head removal, sequential antimicrobial interventions, and rendering. A wide range of beef products and byproducts can be produced from a beef processing plant. Since the focus of this study is the functionality of processing beef, rather than various beef products, we chose the functional unit of beef processing industry to be processing $1000 \mathrm{~kg}$ of live cattle weight (1000 $\mathrm{kg} \mathrm{LCW}$ ). This functional unit reflects the fundamental function of the beef processing industry that slaughters and processes cattle into multiple meat products and by-products. As the focus of this work is not on environmental impact assessment of various beef products but rather on the beef processing plant, we normalize all the beef products into the live cattle weight (i.e., $1000 \mathrm{~kg} \mathrm{LCW}$ ). The EIO based system includes the upstream cutoff systems usually excludes in the process-based system. For example, the construction, equipment maintenance, and various services of beef processing plants are not included in the process-based system due to the data limitation. The details on integrating EIObased and process-based systems can be found in the section on life cycle inventory analysis.

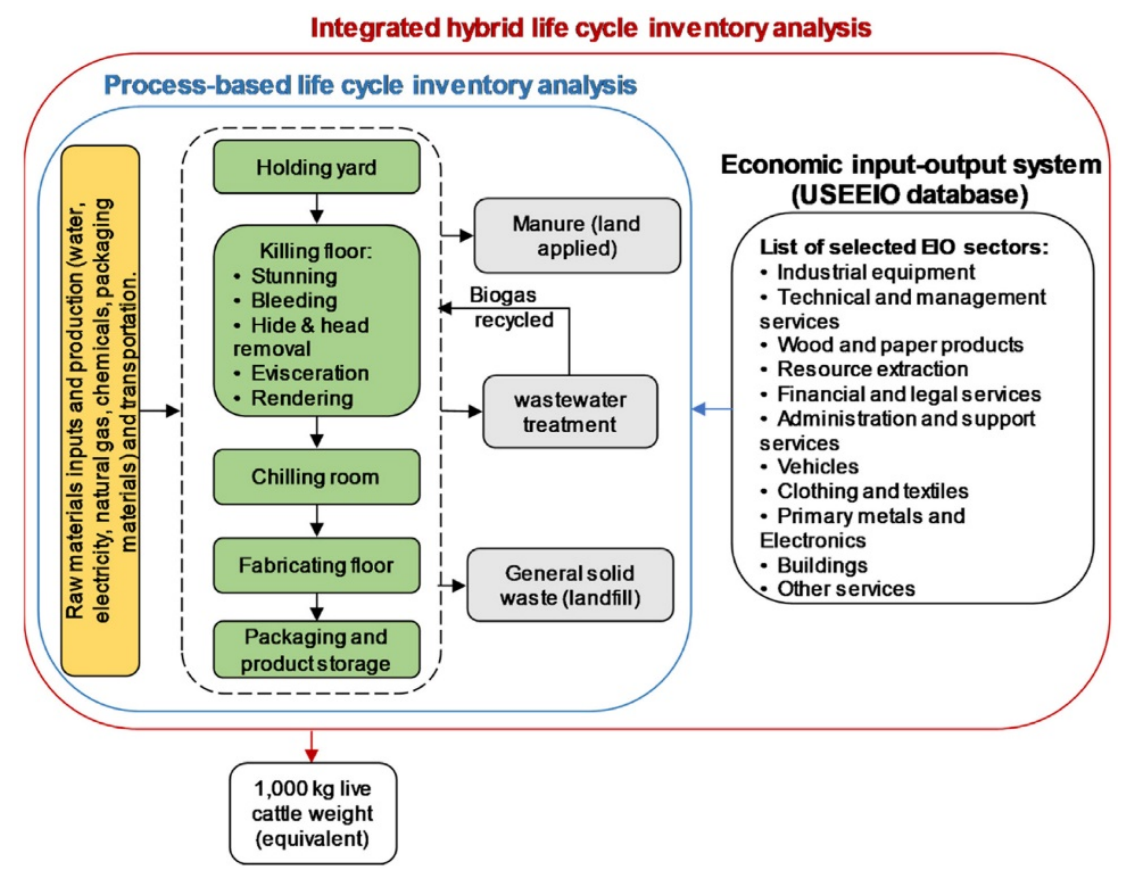

Figure 1. System boundary and methodology framework. The red solid line represents the whole system boundary of hybrid life cycle inventory. The blue solid line represents the process-based life cycle inventory, the black dotted line represents the process flow diagram of slaughterhouses during beef processing. 


\subsection{Life cycle inventory analysis}

The process-specific data (e.g., resource inputs and waste outputs in Fig. 1) are collected from the two commercial US beef processing plants located in the Midwest (Li et al., 2019a, 2018b; Ziara et al., 2018). Those data are further normalized based on the functional unit (1000 kg of live-cattle weight) and processed as the technology matrix coefficient for the process-based system. According to Suh and Huppes (2005), the general mathematical formula of integrated hybrid LCA can be expressed in Equation (1):

$$
E=\left[E_{P} E_{I O}\right]\left[\begin{array}{cc}
A_{P} & -C_{d} \\
-C_{U} & I-A_{I O}
\end{array}\right]^{-1}\left[\begin{array}{l}
y \\
0
\end{array}\right]
$$

Where $\mathrm{E}$ is the total environmental impact vector from both process-based and EIO-based inventory. Ep denotes the coefficient matrix of direct environmental emissions per physical units (e.g., $\mathrm{kg} \mathrm{CO}_{2}$ emissions per $\mathrm{kWh}$ of electricity) from process-based inventory. Eıo represents the coefficient matrix for direct environmental emissions per monetary unit (e.g., $\mathrm{kg} \mathrm{CO} 2$ emissions producing the one-dollar value of a commodity) from the EIO system. Ap symbolizes the technology coefficient matrix (e.g., physical amount of kWh per functional unit of beef processing) for physical flows in process systems. Aio is the direct requirements matrix (e.g., monetary value of financial service sectors to one-dollar of meat) constructed in the USEEIO dataset using the 2007 input-output table derived from the US Bureau of Economic Analysis. $-\mathrm{CU}_{\mathrm{U}}$ is the upstream cut-off flows (e.g., monetary value of financial service sectors to the beef processing process) with a negative sign representing flow direction from EIO system to process system while $-C_{d}$ is the downstream cut-off flows (e.g., the amount of beef processing products to one-dollar of financial service sectors) with a negative sign representing flow direction from process system to EIO system. The flow direction of $-\mathrm{C}_{\mathrm{U}}$ and $-\mathrm{C}_{\mathrm{d}}$ can also be seen in Figure 2. $\mathrm{C}_{\mathrm{U}}$ and $\mathrm{A}_{\mathrm{I}}$ are given in monetary units while the physical flow matrix $T$ and $C_{d}$ are shown in physical units. The final bracket with y and 0 is the demand vector containing the product based on a functional unit (i.e., $1000 \mathrm{~kg}$ live weight beef) that will be supplied to outside of the system.

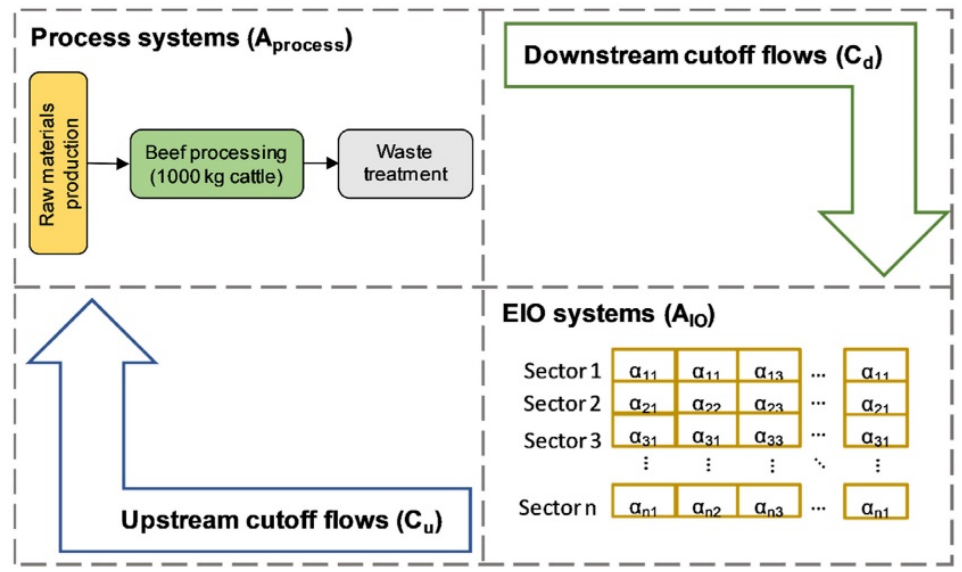

Figure 2. Structure of the integrated hybrid LCA model for beef processing. 
The unit environmental impacts (i.e., Ep and Ero) of process-based LCA (e.g., $\mathrm{kg} \mathrm{CO}_{2} / \mathrm{kWh}$ electricity) were obtained from Ecoinvent v3.3 (https://www.ecoinvent.org/) and EIO-based inventory (e.g., $\mathrm{CO}_{2} / \$$ commodity) were obtained from USEEIO (Yang et al., 2017). The technology coefficient matrix of Ap was obtained via process-specific data in two commercial beef-processing plants in the US Midwest. The technology coefficient matrix of Aro was obtained from the USEEIO dataset developed by the US EPA. The downstream cutoff matrix $C_{d}$ was assumed as zero, since the economic scale of the system for beef processing is negligible compared to the EIO system for the US.

To construct the upstream matrix $\mathrm{Cu}_{\mathrm{U}}$ that represents inputs from the EIO system to the process-based system, five steps in the literature were followed (Wiedmann et al., 2011). First, a concordance matrix matching Ecoinvent processes and EIO sectors was created with 388 rows representing US economic sectors and 14 columns representing processes associated with beef processing. The cells in the concordance matrix are populated with ones if economic sectors and processes are matched and other cells are zeros. Second, a matrix containing unit prices of processes were established from Ecoinvent v3.3 and various publicly available sources and converted from purchaser prices to basic prices in the US currency in 2013 to be consistent with the currency in USEEIO dataset. The conversion ratios of purchaser prices to basic prices of different products were retrieved from the Comprehensive Environmental Data Archive academic version, a peer-reviewed EEIO dataset for potential applications in LCA studies (Suh, 2016). The inflation factors of basic prices at different years are accounted for using average annual producer price indices (PPI) from Federal Reserve Economic Data (https://fred.stlouisfed.org/). The USEEIO was developed based on the IO tables compiled by the US Bureau of Economic Analysis (https://www.bea .gov/) to represent direct requirement commodity input in rows by commodity output in columns. Third, the technical coefficient matrix was directly populated with coefficients from USEEIO in the concordance matrix from the first step. Specifically, the technical coefficients a $a_{i j}$ from USEEIO are populated into cells $C_{i k}$ of the concordance matrix where $i$ is an EIO sector and $\mathrm{j}$ is the economic sector matching the project $\mathrm{k}$. Fourth, the matrix from the third step is element-wise multiped by unit price matrix from the fourth step to produce a price-weighted coefficient matrix. The final step is to check and delete the upstream inputs in the matrix $\mathrm{Cu}$ already covered in process system as the physical units.

\subsection{Impact assessment method}

Tool for Reduction and Assessment of Chemicals and Other Environmental Impacts (TRACI v2.1) was used as the environmental impact assessment method (Bare, 2012). TRACI v2.1 was developed by the US EPA to provide characterization factors for ten impact categories, including ozone depletion, global warming, smog formation, acidification, eutrophication, carcinogen, non-carcinogen, respiratory effects, ecotoxicity, fossil fuel depletion (Fig. 3). The TRACI v2.1 is chosen because it is most relevant to the US geographic region compared to other existing well-established impact assessment methods (e.g., ReCiPe, IMPACT 2002+). The USEEIO developed by the US EPA has also provided the readily available inventory and characterization factors of TRACI v2.1 environmental categories, which allow harmonizing the process-based and EIO-based environmental impacts together. The ten environmental categories were normalized using the environmental baseline impact 
per capita in the US in 2008 (Ryberg et al., 2014). All normalized environmental categories were then weighted to calculate an aggregated single score. Specifically, the single score is calculated using the following Equation (2):

$$
\text { Score }=\sum \frac{I C_{i}}{N r_{i}} \times w_{i}
$$

where $I C_{i}$ is the amount of impact category i for processing $1000 \mathrm{~kg}$ live cattle weight, $N r_{i}$ represents normalization factor for impact category $\mathrm{i}$, and $w_{i}$ denotes the weighting coefficient for impact category i. We applied the annual environmental impacts per capita in America as the normalization factors (Ryberg et al., 2014). The weighting coefficients were obtained from the report of Sustainable Mind methodology that synthesizes weighting coefficients for TRACI v2.1 impact categories (Meijer, 2013). The single score is interpreted as "points" with the unit of the year. A point (Pt), equal to 1,000 millipoint (mPt), is referred to as the overall environmental burden per capita per year.

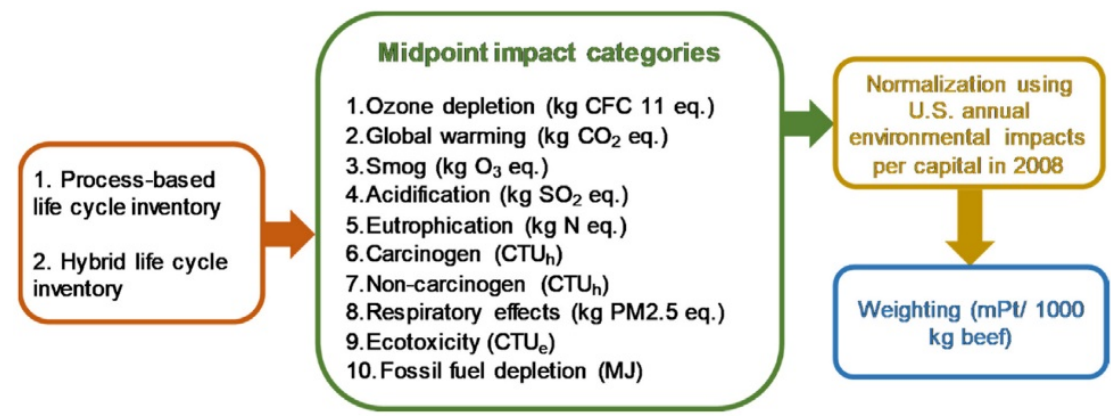

Figure 3. Impact assessment method, normalization, and weighting in this study.

\subsection{Uncertainty and sensitivity analysis}

Various sources of uncertainties and assumptions exist for hybrid LCA studies, such as input data uncertainty (e.g., process specific data, prices) and model uncertainty (e.g., inventory substances, characterization factors). We conducted a Monte Carlo uncertainty analysis to demonstrate the probability distribution of environmental categories under the propagation of various uncertainty sources. In this study, four uncertainty sources are considered, including Ap, Ep, $\mathrm{C}_{\mathrm{U}}$, and Eıo in the hybrid LCA matrix. Due to the limited data, no distribution information is available for the four uncertainty sources. Therefore, assumptions are made to describe parametric probability distributions of those four uncertainty sources based on available data and literature. For Ap (technology coefficient), triangular distribution with $70 \%, 130 \%$ of process-specific data (e.g., $\mathrm{m}^{3} / 1000 \mathrm{~kg} \mathrm{LCW}$, $\mathrm{kWh} / 1000 \mathrm{~kg} \mathrm{LCW}$ ) was assigned as the lower and upper limits, respectively, based on the coefficients of variation in onsite data via one-year data collection ( $\mathrm{Li}$ et al., 2018b). For uncertainty in Ер (direct environmental emissions per physical unit), it is assumed to follow a lognormal distribution with $10 \%$ of mean values as one standard deviation based on precalculations of environmental impacts per unit under the default uncertainty information within the ecoinvent 3.3 (Ciroth et al., 2016). For uncertainty in $C_{u}$ (cutoff monitory 
flows), it is assumed to follow a triangular distribution with 50\%, 150\% of unit prices being the lower and upper limits based on multiple historical prices of different commodities (US EIA, 2018a, 2018b; USDA AMS, 2018). For uncertainty in Ero (direct environmental emissions per monitory flows), the pedigree matrix provided by USEEIO assessing the data quality of the Ero is used to construct its distribution.

To investigate the impacts of input parameters on the final results, we performed global sensitivity analysis using Sobol method to evaluate the impacts on outputs by changing the input parameters, including the amount of onsite energy usage (i.e., natural gas and electricity) and product price, to demonstrate the actual range of results can change, while keeping other parameters following their corresponding intrinsic distributions (Groen et al., 2017). The Sobol indices decompose the variance of outputs into orthogonal terms independent of each other. The Sobol's main effect (SME) index calculates the main variance contributed by the first-order term of parameters while the Sobol's total effect (STE) index calculates total variance explained by the parameters, including interactions among parameters. In the case of the linearity of the integrated hybrid LCA model in this study, the SME index is approximate to the STE index since all interaction terms between variables are approximately zero. Detailed steps and sampling algorithms implementing the Sobol method to the LCA model can be found in the work of Groen et al. (2017). The uncertainty and sensitivity analyses were conducted in Python and the codes are accessible from the authors upon request.

\section{Results and discussion}

\subsection{Process-based LCA}

The contribution of various processes during beef processing to the various environmental life cycle impacts are shown in Figure 4. The x-axis shows the ten TRACI v2.1 environmental categories and the left $y$-axis presents process contribution by percentage and the right $y$-axis is the normalized value of each environmental category. The normalized values of various environmental categories are calculated by the ratio of the environmental burdens of each environmental category to the total environmental burden shared by one American in the year 2008 (Ryberg et al., 2014). 


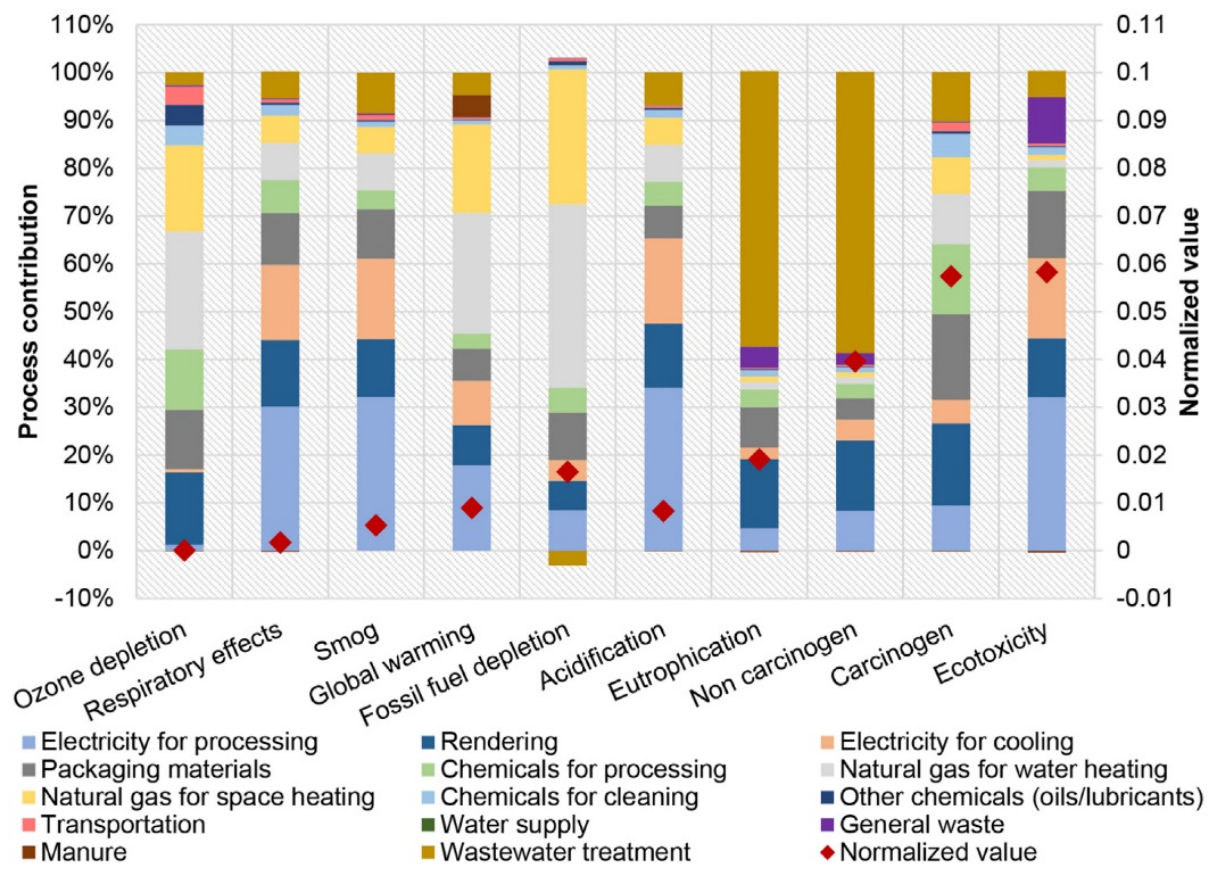

Figure 4. Contributions of process-based environmental impacts of US beef processing. All subprocesses shown in the legend are from the boundary of process-based inventory shown in Figure 1.

Table 1 provides numerical values of environmental categories before and after normalization. The middle panel of Table 1 contains the values of impact categories with the physical units of three groups: process-based, EIO system, and total. The right panel consists of normalized values that divide the sum of process-based and EIO system in the middle panel by external normalization factors, i.e. annual environmental impact per capita reported by Ryberg et at. (2014). The overall global warming for processing $1000 \mathrm{~kg}$ live cattle weight (LCW) at plant is estimated at $250 \mathrm{~kg} \mathrm{CO}$-eq (Table 1). Asem-Hiablie et al. (2019) conducted a detailed LCA study on the US beef supply chain from cradle to farm gate to post-farm gate and chose $1 \mathrm{~kg}$ of consumed and boneless beef as function unit, which is equivalent to $3.45 \mathrm{~kg}$ live weight beef. After converting the results from that study to the same functional unit (i.e., $1000 \mathrm{~kg}$ LCW) selected in this study, a similar value of $237 \mathrm{~kg}$ $\mathrm{CO}_{2-\mathrm{eq}} / 1000 \mathrm{~kg} \mathrm{LCW}$ was reported for the sectors of packaging and case-ready using system boundary similar to those used by the source (Rotz et al., 2019). However, it is worth noting that the processing and packing stage accounts for only $1.7 \%$ of the whole beef supply chain. Another study focused on the environmental impact of beef production in Mexico also concluded that about $255 \mathrm{~kg} \mathrm{CO}$-eq $/ 1000 \mathrm{~kg} \mathrm{LCW}$ was produced during the beef processing stage of an intensive system in which beef cattle are raised in a feedlot (Huerta et al., 2016). The use of electricity and natural gas use are key resources for implementing various antimicrobial interventions to ensure beef safety (Li et al., 2019b) and contribute to the most global warming because of $\mathrm{CO}_{2}$ and $\mathrm{CH}_{4}$ from the combustion of fossil fuels (Fig. 4). 


\begin{tabular}{|c|c|c|c|c|c|}
\hline Impact category & Unit & $\begin{array}{c}\text { Process-based } \\
\text { system }\end{array}$ & EIO systems & Total & $\begin{array}{c}\text { Normalized } \\
\text { value (dimen- } \\
\text { sionless) } \\
\end{array}$ \\
\hline Ozone depletion & kg CFC-11 eq & 4.99E-06 & $6.9 \mathrm{E}-06$ & $1.2 \mathrm{E}-05$ & 7.37E-05 \\
\hline Respiratory effects & kg PM2.5 eq & 4.18E-02 & $1.8 \mathrm{E}-02$ & 5.9E-02 & $2.45 \mathrm{E}-03$ \\
\hline Smog & $\mathrm{kg} \mathrm{O}_{3} \mathrm{eq}$ & $7.39 \mathrm{E}+00$ & $1.8 \mathrm{E}+00$ & $9.2 \mathrm{E}+00$ & $6.61 \mathrm{E}-03$ \\
\hline Global warming & $\mathrm{kg} \mathrm{CO}_{2} \mathrm{eq}$ & $2.17 \mathrm{E}+02$ & $3.5 \mathrm{E}+01$ & $2.5 \mathrm{E}+02$ & $1.04 \mathrm{E}-02$ \\
\hline Fossil fuel depletion & MJ surplus & $3.10 \mathrm{E}+02$ & $1.1 \mathrm{E}+02$ & $4.2 \mathrm{E}+02$ & 2.25E-02 \\
\hline Acidification & $\mathrm{kg} \mathrm{SO}_{2} \mathrm{eq}$ & 7.53E-01 & $1.0 \mathrm{E}-01$ & 8.6E-01 & $9.41 \mathrm{E}-03$ \\
\hline Eutrophication & $\mathrm{kg} \mathrm{N}$ eq & 4.13E-01 & 3.3E-02 & 4.5E-01 & $2.06 \mathrm{E}-02$ \\
\hline Non-carcinogen & CTUh & $4.16 \mathrm{E}-05$ & $3.2 \mathrm{E}-08$ & 4.2E-05 & $3.96 \mathrm{E}-02$ \\
\hline Carcinogen & CTUh & 3.03E-06 & $6.5 \mathrm{E}-09$ & $3.0 \mathrm{E}-06$ & $5.75 \mathrm{E}-02$ \\
\hline Ecotoxicity & CTUe & $6.45 \mathrm{E}+02$ & $2.3 \mathrm{E}+00$ & $6.5 \mathrm{E}+02$ & $5.85 \mathrm{E}-02$ \\
\hline
\end{tabular}

The result of the acidification impact in this work is $0.86 \mathrm{~kg} \mathrm{SO}$-eq $/ 1000 \mathrm{~kg} \mathrm{LCW}$ while the reported value from Rotz et al. (2019) is a similar value of $1.25 \mathrm{~kg} \mathrm{SO}$-eq $/ 1000 \mathrm{~kg} \mathrm{LCW}$ on the same functional unit. Electricity also contributes to most of ecotoxicity due to copper and zinc emissions to water. $80 \%$ of carcinogen impact is caused by the emissions of chromium VI to water from the production of chemicals, natural gas, and electricity. The process of wastewater treatment contributes most of the eutrophication $(56 \%)$ because of nutrient emissions (i.e., BOD, ammonia, phosphorus) and non-carcinogen (58\%) because of heavy metals emitted to agricultural soil when applying sludge on the farmland.

Carcinogen and ecotoxicity are the two major impacts when scaling to the average impacts per capita in the US, each accounting around 0.058 . This means that the environmental impacts of ecotoxicity and carcinogen because of processing $1000 \mathrm{~kg}$ LCW is equivalent to $5.8 \%$ of ecotoxicity and carcinogen impacts shared by one American in the year of 2008 . A similar interpretation applies to other environmental categories. The non-carcinogen impact of processing $1000 \mathrm{~kg}$ live weight beef is around $4.0 \%$, eutrophication $2.1 \%$, and fossil fuel depletion $2.5 \%$. Other remaining environmental impacts are all under $1 \%$. Note that US beef consumption per capita is $35.9 \mathrm{~kg}$ carcass weight in 2016, equivalent to $57.7 \mathrm{~kg}$ live cattle weight assuming $62 \%$ of live cattle can be produced as carcass (USDA ERS, 2018). The coefficient of $0.0577(57.7 \mathrm{~kg} / 1000 \mathrm{~kg})$ should be further multiplied to evaluate the contrition of environmental impacts of beef processing due to the same amount of beef per US capita. For example, $0.33 \%$ of ecotoxicity and carcinogen impacts shared by one American is due to beef processing. Although normalized values are useful for relative comparison, the environmental impacts shared by one American are from 2008 while the primary data of beef processing plants are collected from 2016.

\subsection{Integrated hybrid LCA}

In this work, the results of the integrated hybrid LCA across ten TRACI environmental categories are presented in Figure 5. Compared to most hybrid LCA studies that focus only on one or two environmental categories (Gao and You, 2018; Wiedmann et al., 2011; Yao et al., 2014), this work expands the spectrum of environmental categories to be fully 
compatible with the TRACI v2.1 in the case of US beef processing. It is noted that the USEEIO database contains 389 specific sectors. Therefore, the developers of USEEIO further group 389 sectors into different categories. For example, the group of industrial equipment contains a total of 50 specific EIO sectors, such as "valve and fittings other than plumbing", "construction machinery manufacturing", and many others. For details of each sector group, we recommend the audience to review the work of Yang et al. (2017). The eleven sector groups shown in Figures 5 and 7 are presented in this work. The other sector groups are not discussed in this work because the direct environmental impacts from those groups are shown as zeros in the results of integrated hybrid LCA. However, as all sectors in EIO system are interconnected, those sector groups not shown in this study can also indirectly impact on the group sectors shown in this work. For example, the sector groups of "furniture" and "medical supplies" (not discussed in this work) are connected with the group "administration and support services." Therefore, the impact of administration and support services already contains environmental impacts from "furniture" and "medical supplies." This is realized through the requirements matrix Aı. As shown in Figure 5, the impacts of ecotoxicity, carcinogen, and non-carcinogen are all accounted from the processbased system. The impacts of eutrophication, acidification, and global warming are primarily contributed by the process-based system (> 80\%). The major environmental impacts contributed by the EIO system are ozone depletion (67\%), respiratory effects (42\%), fossil fuel depletion (38\%), and smog (28\%), mainly due to the environmental impacts from the sectors of wood and papers, industrial equipment, and technical and management services (which are not included in the process-based data).

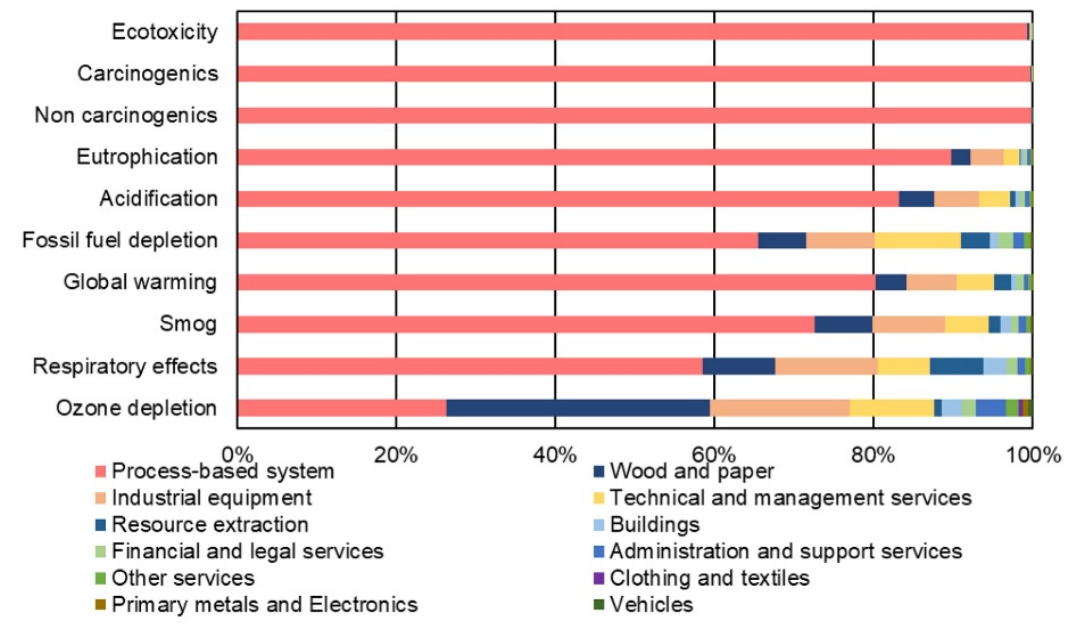

Figure 5. Integrated hybrid LCA midpoint results of the US beef processing. Process contributions of the process-based system are provided in Figure 4.

The beef industry in North America has been committed to benchmarking and advancing the sustainability of beef production by adopting strategies (Maia de Souza et al., 2017). One of the most important strategies is to develop science-based frameworks and indicators to measure sustainability. The integrated hybrid LCA approach in this work can serve 
as a promising framework that comprehensively quantifies the environmental impact for US beef processing. Traditional environmental concerns of US beef processing focus on its onsite intensive water and energy use as well as order wastewater emissions. The result in Figure 5 highlights the value of requiring suppliers and service providers to become more sustainable may result in a notable improvement in certain categories. For example, the considerable contribution of EIO system on the impacts of ozone depletion and respiratory effects implies substantial mitigation opportunities for reducing impacts. Studies have also shown that companies and corporations can follow effective environmental management systems and supplier engagement to improve the environmental sustainability not only onsite but also across their supply chains (Daud et al., 2019; Prosman and Sacchi, 2016; Tidy et al., 2016).

The aggregated environmental single score, based on the summation of normalized and weighted values from TRACI environmental categories, of the hybrid LCA during the US beef processing with the bar of pie demonstrating the breakdown of environmental single score from various economic sectors in the EIO system is shown in Figure 6. As can be seen in Figure 6, most of the environmental single score is accounted in the process-based system $(89.6 \%)$ while $10.4 \%$ of the environmental single score comes from the EIO system (impacts from inputs not included in process-level data). This is because the environmental single score is mainly caused by key process-based inventory, such as natural gas and electricity use. Within the EIO-based system (10.4\%), the industrial equipment sector is the biggest contributor (3.0\%), followed by technical and management services (2.7\%) and wood and papers $(2.1 \%)$. Other remaining sectors account for $2.6 \%$ in total.

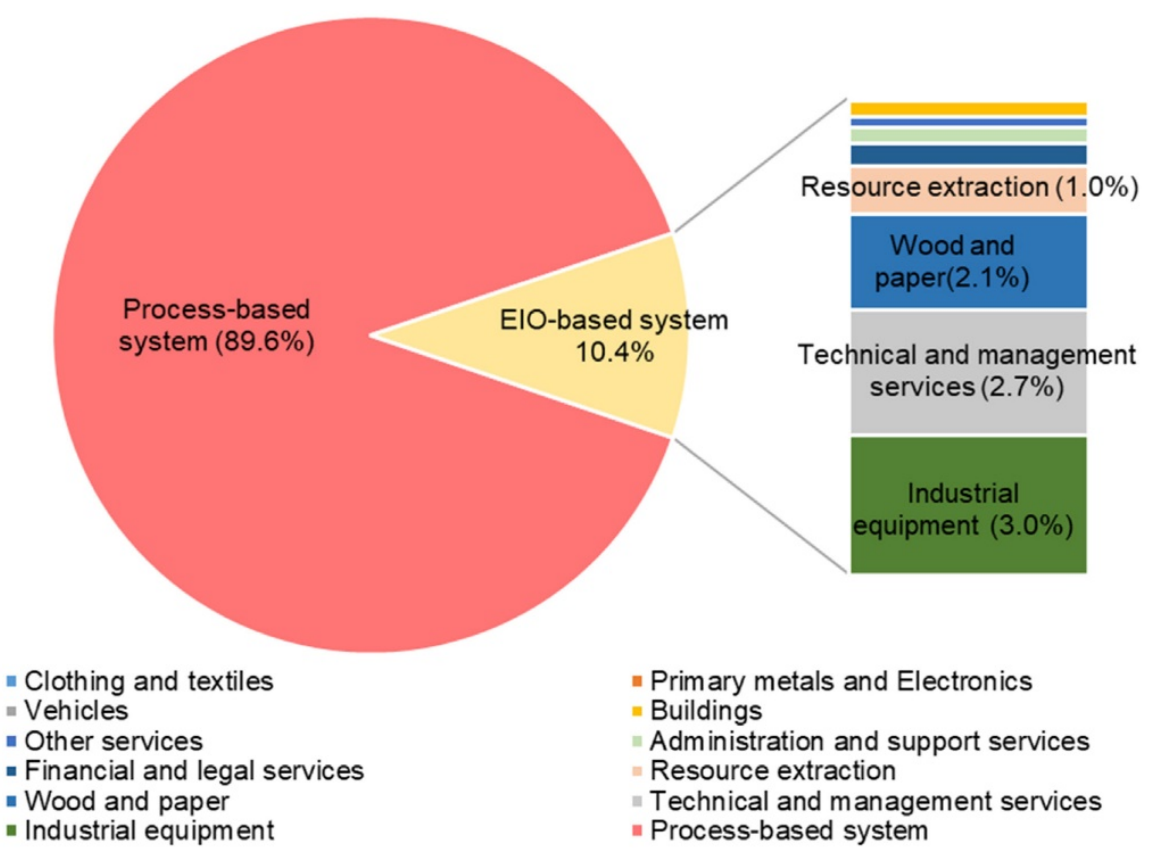

Figure 6. Integrated hybrid LCA environmental single score of the US beef processing. Process contributions of the process-based system are provided in Figure 4. 


\subsection{Uncertainty and sensitivity analysis}

In Figure 7, the probability distributions of ten TRACI environmental categories are shown in the violin plot while the median and quartile values are displayed in the box plot inside the violin. The thickness of the violin shape represents the frequency of the sample points. Note that the units in the $x$-axis are displayed in their corresponding physical units of the environmental categories (e.g., kg CDC-11 eq) so that the y-axis positions of different categories cannot be compared. The results show that all environmental categories follow the bell-shaped curve. The great deal of variability for each impact category in Figure 7 implies mitigation opportunities for reducing impacts. The categories of ozone depletion, ecotoxicity, and single score by EIO have a flatter and wider bell-shaped curve because they are involved with more parameter uncertainty sources. On the far right of Figure 7, the percentage contribution of EIO system to the overall single score is provided. The overall contribution of EIO system ranges from $6.4 \%\left(3.2^{*} 2\right)$ to $15.4 \%\left(7.7^{*} 2\right)$ under uncertainty.

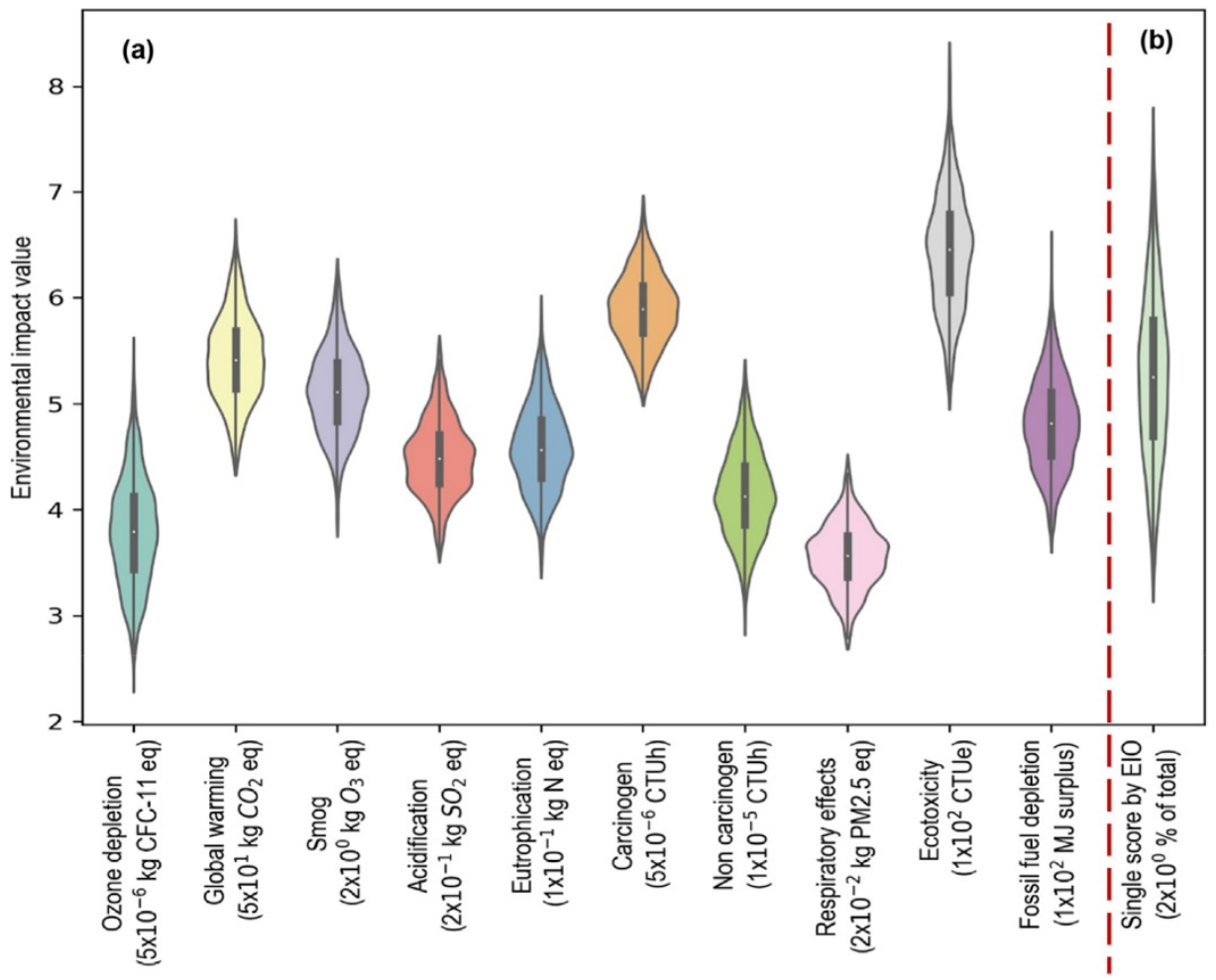

Fig. 7. Violin plot of environmental categories representing the sampling distribution from Monte Carlo simulation (10,000 runs). Environmental impact value refers to the numerical value in different impact categories with their corresponsive physical units. For example, the environmental value of ozone depletion ranges 2.3 to 5.7 (i.e., the range of its violin plot) multiplied by its physical unit (i.e., $5 \times 10^{-6} \mathrm{~kg}$ CDC-11 eq). The environmental categories on the left side (a) of the red dashed line are midpoint while the one on the right side (b) is the contribution of a single score from the EIO system that normalizes and weights all midpoint categories into a single value. 
To further evaluate the impacts of key variables on the results of each environmental category, global sensitivity analysis (GSA) was conducted on ten TRACI impact categories and the aggregated environmental single score as shown in Figure 8. The sensitivity index in the y-axis represents how much the output variance key parameters explains. For example, 0.95 of the sensitivity index for the beef price on ozone depletion means that $95 \%$ of the variance in the ozone depletion result is from the beef price. For brevity, the parameters that their sensitivity indexes are less than $2 \%$ were grouped as "others."
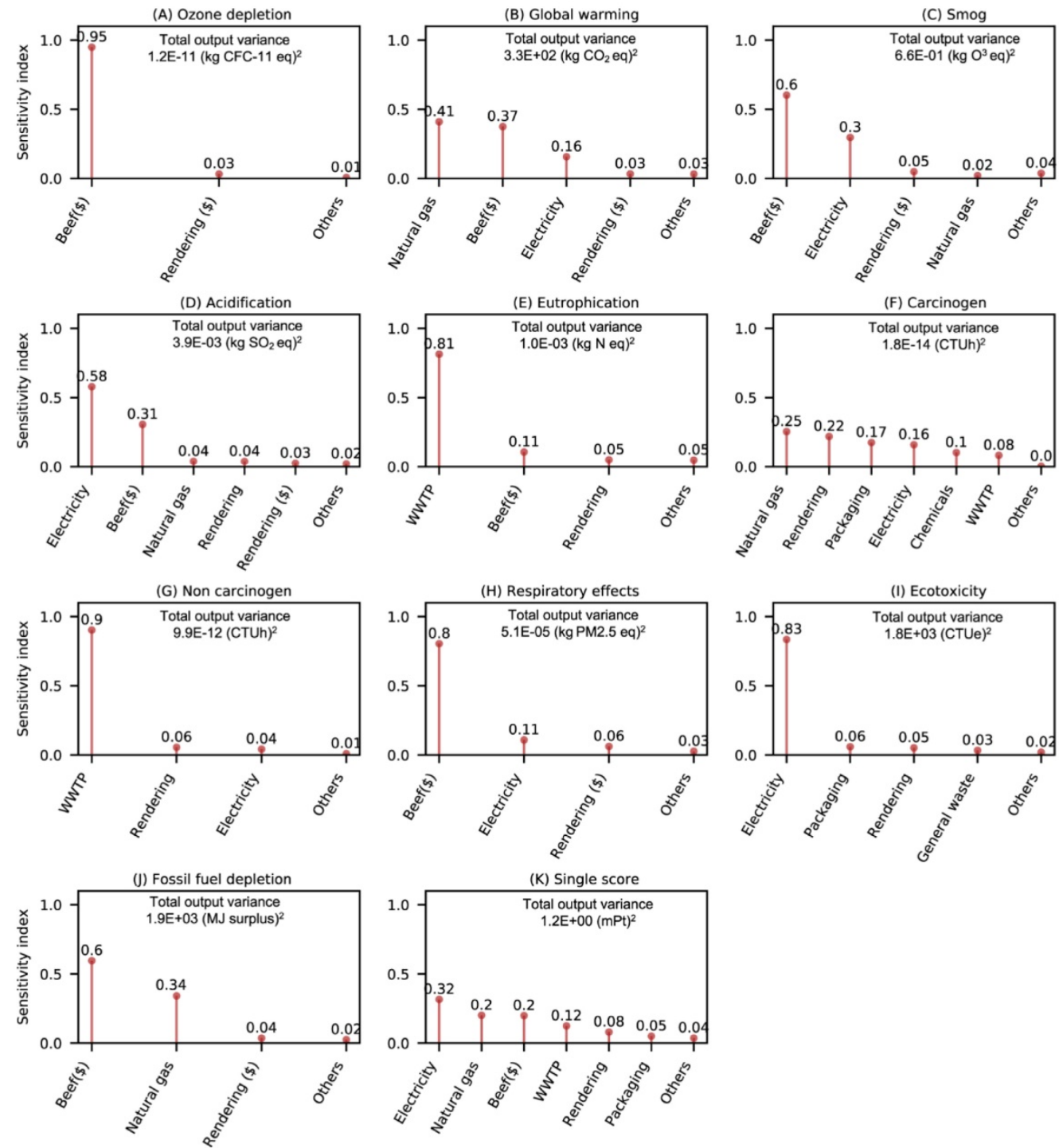

Fig. 8. Contribution to output variance for Sobol's total sensitivity index of the selected inventory parameters (i.e., usage and prices). Note: WWT: wastewater treatment. The categories on $\mathrm{x}$-axis with $(\$)$ refer to the variability of its price, otherwise refer to the variability of its physical data. 
The key parameters considered for the GAS include the process-based foreground data (e.g., the physical amount of electricity, natural gas, chemicals, packaging materials) that are directly linked to the processes during the beef processing and the prices of those foreground data. In Figure 8, each subplot (A to J) represents the results of GSA on one environmental indicator from TRACI impact categories while Figure $8(\mathrm{~K})$ represents the GSA on the aggregated single score. The beef price (\$) has dominant sensitivity impact (explaining $>50 \%$ of total output variance) in the categories of ozone depletion $(95 \%)$, smog $(60 \%)$, respiratory effects $(80 \%)$, and fossil fuel depletion $(60 \%)$, and notable impact (explaining between 20 and 50\%) in the categories of global warming (37\%) and acidification (31\%). The physical amount of electricity has a dominant sensitivity impact on acidification (58\%) and ecotoxicity (83\%) and nonnegligible contribution to smog (30\%) and carcinogen (16\%). The physical amount of natural gas has noticeable impacts of global warming (41\%) and fossil fuel depletion (34\%). $90 \%$ variance of noncarcinogen is explained by heavy metal contents from the sludge due to wastewater treatment. Overall, the aggregated single score is mostly impacted by the four key parameters: (1) the amount of electricity usage (32\%), (2) the amount of natural gas usage (20\%), (3) the beef price (20\%), and (4) wastewater treatment $(12 \%)$.

\section{Conclusions}

To our knowledge, this work is the first analysis to apply integrated hybrid LCA in the food processing industry. Moreover, this work fully incorporates ten TRACI environmental impact categories in the integrated hybrid LCA, which is helpful for bridging the gap, as most existing hybrid LCA studies focus on one or two environmental categories (e.g., life cycle carbon or energy footprint). The integrated hybrid LCA complements the system boundary of process-based LCA and can comprehensively quantify the environmental impacts and identifies the relative scale of environmental impacts that may be caused by the suppliers and service providers that are not captured by a process-based analysis. By estimating the environmental impact from these suppliers and service providers, it can help justify the importance of greening the US beef processing's supply chain. The hybrid LCA framework applied in this study can be easily adapted to other food industries to enhance our understanding of embedded environmental impacts from EIO systems.

We applied the USEEIO database for the inventory from EIO system, which allows us to consider all ten TRACI environmental categories. We further normalized and weighted the ten categories into the aggregated environmental single score. Monte Carlo simulations were performed to simulate the distributions of all TRACI categories as well as the single score contributed by EIO systems. The global sensitivity analysis considers the ranges and distributions of all resource usage rates and their prices and identified electricity, natural gas, and wastewater treatment from process, and beef price from the EIO system explains the most variance of all ten TRACI environmental categories and the environmental single score.

Based on process-based analysis, it can be identified that management practices should focus on increasing energy and water efficiency (e.g., onsite electricity, natural gas, water use) and minimizing nutrient emissions and heavy metal contents in sludge. Specific 
effective sustainable measurements include improving electricity efficiency for cooling system by optimizing compressor speed and recycling water in some processes (e.g., hide wash cabinet) without compromising food safety. Based on the economic contribution analysis, selecting suppliers of industrial equipment and service providers of technical and management services with more sustainable practices may result in a notable improvement in certain environmental categories (i.e., ozone depletion, respiratory effects, fossil fuel depletion, smog).

Like other LCA studies, our work has some limitations. First, the process-based inventory data were collected from two commercial beef processing plants located in the Midwest. Inventory data from more plants are needed to represent the whole US beef processing industry and to better understand the variability of operations, which might help identify mitigation opportunities for reducing impacts. In addition, the uncertainty sources evaluated in this work include only the uncertainty of inventory data. The uncertainty information of characterization factors used in TRACI v2.1 method is not well studied so that the most uncertainty analysis of LCA studies are not fully captured in all the variability of results. The dataset of economic systems used in this work is the USEEIO from US EPA, which represents the requirement relationship among domestic US economic sectors. However, the economy is connected globally nowadays. Therefore, a global, detailed multiregional input-output database is necessary, such as exiobase (https://exiobase .eu/). Such an existing database does not have readily available environmental categories consistent with TRACI v2.1. Further data processing to connect the inventory data with the TRACI v.2.1 characterization factors needs to be addressed in future studies.

Declaration of competing interest - The authors declare that they have no known competing financial interests or personal relationships that could have appeared to influence the work reported in this paper.

Authorship contribution statement - Shaobin Li: conceptualization, methodology, formal analysis, visualization, writing - original draft, writing — review and editing. Yuwei Qin: methodology, formal analysis, writing - review and editing. Jeyamkondan Subbiah: conceptualization, writing - review and editing, project administration, funding acquisition. Bruce Dvorak: conceptualization, formal analysis, writing - original draft, writing - review and editing, supervision, project administration.

Acknowledgments - This work was funded by the National Institute of Food and Agriculture, US Department of Agriculture [2012-68003-30155]. We gratefully thank the Maude Hammond Fling Fellowship at the University of Nebraska-Lincoln for supporting Shaobin Li for his PhD studies during the 2018-2019 academic year. We also appreciate Dr. Sangwon Suh from the University of California, Santa Barbara for providing his insights and suggestions on constructing the integrated hybrid matrix of this work.

\section{References}

Asem-Hiablie, S., Battagliese, T., Stackhouse-Lawson, K.R., Alan Rotz, C., 2019. A life cycle assessment of the environmental impacts of a beef system in the USA. Int. J. Life Cycle Assess. 24, 441e455. https://doi.org/10.1007/s11367-018-1464-6 
Bare, J.C., 2012. Tool for the Reduction and Assessment of Chemical and Other Environmental Impacts (TRACI), Version 2.1 User's Guide. US Environmental Protection Agency, Cincinnati, OH.

Battagliese, T., Andrade, J., Vinas, R., Stackhouse-lawson, K., Rotz, C.A., Dillon, J., 2015. Submission for Verification of Eco-Efficiency Analysis under NSF Protocol P352, Part B US Beef-Phase 2 Eco-Efficiency Analysis.

Bilec, M., Ries, R., Matthews, H.S., Sharrard, A.L., 2006. Example of a hybrid life-cycle assessment of construction processes. J. Infrastruct. Syst. 12, 207e215. https://doi.org/10.1061/(ASCE)10760342 (2006)12:4(207)

Bullard, C.W., Penner, P.S., Pilati, D.A., 1978. Net energy analysis. Handbook for combining process and input-output analysis. Resour. Energy 1, 267e313. https://doi.org/10.1016/0165-0572(78)90008-7

Charles, H., Godfray, J., Aveyard, P., Garnett, T., Hall, J.W., Key, T.J., Lorimer, J., Pierrehumbert, R.T., Scarborough, P., Springmann, M., Jebb, S.A., 2018. Meat consumption, health, and the environment. Science 80, 361. https://doi.org/10.1126/science.aam5324 eaam5324

Ciroth, A., Muller, S., Weidema, B., Lesage, P., 2016. Empirically based uncertainty factors for the pedigree matrix in ecoinvent. Int. J. Life Cycle Assess. 21, 1338e1348. https://doi.org/10.1007/ s11367-013-0670-5

Crawford, R.H., Bontinck, P.-A., Stephan, A., Wiedmann, T., Yu, M., 2018. Hybrid life cycle inventory methods-a review. J. Clean. Prod. 172, 1273e1288. https://doi.org/10.1016/J.JCLEPRO.2017.10.176

Daud, S., Yusof, N., Mokhtar, M., 2019. The effectiveness of the environmental management system (EMS) implementation in green supply chain: a case study. KnE Soc. Sci. https://doi.org/10.18502 /kss.v3i22.5105

Eshel, G., Shepon, A., Makov, T., Milo, R., 2014. Land, irrigation water, greenhouse gas, and reactive nitrogen burdens of meat, eggs, and dairy production in the United States. Proc. Natl. Acad. Sci. Unit. States Am. 111, 11996e12001. https://doi.org/10.1073/pnas.1402183111

Foods, Smithfield, 2019. Sustainability Policies I Smithfield Foods USA. Global Food Company. https://www .smithfieldfoods.com/sustainability/policies. Accessed 9.18.19.

Gao, J., You, F., 2018. Integrated hybrid life cycle assessment and optimization of shale gas. ACS Sustain. Chem. Eng. 6, 1803e1824. https://doi.org/10.1021/acssuschemeng.7b03198

Groen, E.A., Bokkers, E.A.M., Heijungs, R., de Boer, I.J.M., 2017. Methods for global sensitivity analysis in life cycle assessment. Int. J. Life Cycle Assess. 22, 1125e1137. https://doi.org/10.1007/s11367016-1217-3

Huerta, A.R., Güereca, L.P., Lozano, M.D.L.S.R., 2016. Environmental impact of beef production in Mexico through life cycle assessment. Resour. Conserv. Recycl 109, 44e53. https://doi.org/10.1016 /J.RESCONREC.2016.01.020

JBS Beef, 2019. JBS sustainability [WWW document]. https://jbssa.com/sustainability/. Accessed 9.18.19.

Kim, Daesoo, Thoma, Greg, Nutter, Darin, Milani, Franco, Ulrich, Rick, Norris, Greg, Kim, D., Thoma, G., Ulrich, R., Martin, R.E., Nutter, D., Norris, G., Milani, F., 2013. Life cycle assessment of cheese and whey production in the USA. Int. J. Life Cycle Assess. 18, 1019e1035. https://doi .org/10.1007/s11367-013-0553-9

Li, S., Kinser, C., Ziara, R.M.M., Dvorak, B., Subbiah, J., 2018a. Environmental and economic implications of food safety interventions: life cycle and operating cost assessment of antimicrobial systems in US beef packing industry. J. Clean. Prod. 198, 541e550. https://doi.org/10.1016/J.JCLEPRO .2018.07.020

Li, S., Ziara, R.M.M., Dvorak, B., Subbiah, J., 2018b. Assessment of water and energy use at process level in the US beef packing industry: case study in a typical US large-size plant. J. Food Process. Eng. 41, e12919. https://doi.org/10.1111/jfpe.12919 
Li, S., Subbiah, J., Dvorak, B., 2019a. Environmental and occupational impacts from US beef slaughtering are of same magnitude of beef foodborne illnesses on human health. Environ. Int. 129, 507e516. https://doi.org/10.1016/J.ENVINT.2019.05.051

Li, S., Zhilyaev, S., Gallagher, D., Subbiah, J., Dvorak, B., 2019b. Sustainability of safe foods: joint environmental, economic and microbial load reduction assessment of antimicrobial systems in US beef processing. Sci. Total Environ. 691, 252e262. https://doi.org/10.1016/J.SCITOTENV.2019 .07 .064

Maia de Souza, D., Petre, R., Jackson, F., Hadarits, M., Pogue, S., Carlyle, C., Bork, E., McAllister, T., 2017. A review of sustainability enhancements in the beef value chain: state-of-the-art and recommendations for future improvements. Animals 7, 26. https://doi.org/10.3390/ani7030026

Meijer, J., 2013. SM2013 Methodology and Database.

Mogensen, L., Lan, T., Nguyen, T., Madsen, N.T., Pontoppidan, O., Preda, T., Hermansen, J.E., 2016. Environmental impact of beef sourced from different production systems-focus on the slaughtering stage: input and output. J. Clean. Prod. 133, 284e293. https://doi.org/10.1016/j.jclepro.2016 .05 .105

National Cattleman's Beef Association, 2016. Industry statistics - beef USA. http://www.beefusa.org /beefindustrystatistics.aspx. Accessed 4.15.19.

Peters, G.M., Rowley, H.V., Wiedemann, S., Tucker, R., Short, M.D., Schulz, M., 2010. Red meat production in Australia: life cycle assessment and comparison with overseas studies. Environ. Sci. Technol. 44, 1327e1332. https://doi.org/10.1021/es901131e

Prosman, E.J., Sacchi, R., 2016. New environmental supplier selection criteria for circular supply chains: lessons from a consequential LCA study on waste recovery. J. Clean. Prod. 172, 2782e2792. https://doi.org/10.1016/j.jclepro.2017.11.134

Ramaswami, A., Hillman, T., Janson, B., Reiner, M., Thomas, G., 2008. A demand-centered, hybrid life-cycle methodology for city-scale greenhouse gas inventories. Environ. Sci. Technol. 42, 6455e6461. https://doi.org/10.1021/es702992q

Rotz, C.A., Asem-Hiablie, S., Place, S., Thoma, G., 2019. Environmental footprints of beef cattle production in the United States. Agric. Syst. 169, 1e13. https://doi.org/10.1016/J.AGSY.2018.11.005

Roy, P., Nei, D., Orikasa, T., Xu, Q., Okadome, H., Nakamura, N., Shiina, T., 2009. A review of life cycle assessment (LCA) on some food products. J. Food Eng. 90, 1e10. https://doi.org/10.1016 /j.jfoodeng.2008.06.016

Ryberg, M., Vieira, M.D.M., Zgola, M., Bare, J., Rosenbaum, R.K., 2014. Updated US and Canadian normalization factors for TRACI 2.1. Clean Technol. Environ. Pol. 16, 329e339. https://doi.org /10.1007/s10098-013-0629-z

Silva, V.L., Sanjuán, N., 2019. Opening up the black box: a systematic literature review of life cycle assessment in alternative food processing technologies. J. Food Eng. 250, 33e45. https://doi.org /10.1016/j.jfoodeng.2019.01.010

Steinfeld, H., Gerber, P., Wassenaar, T., Vincent, C., Rosales, M., Haan, C. de, 2006. Livestock's Long Shadow: Environmental Issues and Options. Food and Agriculture Organization of the United Nations.

Suh, S., 2016. Comprehensive Environmental Data Archive (CEDA) v.5. IERS, LLC, Santa Barbara, CA.

Suh, S., Huppes, G., 2005. Methods for life cycle inventory of a product. J. Clean. Prod. 13, 687e697. https://doi.org/10.1016/j.jclepro.2003.04.001

Tidy, M., Wang, X., Hall, M., 2016. The role of Supplier Relationship Management in reducing Greenhouse Gas emissions from food supply chains: supplier engagement in the UK supermarket sector. J. Clean. Prod. 112, 3294e3305. https://doi.org/10.1016/j.jclepro.2015.10.065 
Tyson Foods, 2017. Sustaining Our World-Sustainability Report.

US EIA, 2018a. US Natural gas prices. https://www.eia.gov/dnav/ng/ng_pri_sum_dcu_nus_a.htm. Accessed 5.17.18.

US EIA, 2018b. Electricity data browser - net generation for all sectors. https://www.eia.gov/electricity/data/browser/. Accessed 5.17.18.

USDA AMS, 2018. National daily boxed beef cutout and boxed beef cuts. https://www.ams.usda.gov /mnreports/lm_xb403.txt. Accessed 1.30.18.

USDA ERS, 2018. Food availability (per capita) data system. https://www.ers.usda.gov/data-products /food-availability-per-capita-data-system/food-availability-per-capita-data-system/\#Food.Availability

USDA FAS, 2020. Livestock and Poultry: World Markets and Trade.

USDA NASS, 2015. Census of Agriculture-Highlights.

Wiedmann, T.O., Suh, S., Feng, K., Lenzen, M., Acquaye, A., Scott, K., Barrett, J.R., 2011. Application of hybrid life cycle approaches to emerging energy technologies-The case of wind power in the UK. Environ. Sci. Technol. 45, 5900e5907. https://doi.org/10.1021/es2007287

Yang, Y., Ingwersen, W.W., Hawkins, T.R., Srocka, M., Meyer, D.E., 2017. USEEIO: a new and transparent United States environmentally extended input-output model. J. Clean. Prod. 158, 308e318. https://doi.org/10.1016/J.JCLEPRO.2017.04.150

Yao, Y., Chang, Y., Masanet, E., 2014. A hybrid life-cycle inventory for multicrystalline silicon PV module manufacturing in China. Environ. Res. Lett. 9, 114001. https://doi.org/10.1088/17489326/9/11/114001

Yu, M., Wiedmann, T., 2018. Implementing hybrid LCA routines in an input-output virtual laboratory. J. Econ. Struct. 7, 33. https://doi.org/10.1186/s40008-018-0131-1

Zhai, P., Williams, E., 2010. Dynamic hybrid life cycle assessment of energy and carbon of multicrystalline silicon photovoltaic systems. Environ. Sci. Technol. 44, 7950e7955. https://doi.org/10.1021 /es1026695

Zhao, S., You, F., 2019. Comparative life-cycle assessment of Li-ion batteries through process-based and integrated hybrid approaches. ACS Sustain. Chem. Eng. 7, 5082e5094. https://doi.org/10.1021 /acssuschemeng.8b05902

Ziara, R.M.M., Li, S., Dvorak, B., Subbiah, J., 2016. Water and energy use of antimicrobial interventions in a mid-size beef packing plant. Appl. Eng. Agric. 32, 863e869. https://doi.org/10.13031 /aea.32.11615

Ziara, R.M.M., Li, S., Subbiah, J., Dvorak, B., 2018. Characterization of wastewater in two US Cattle slaughterhouses. Water Environ. Res. 90, 851e863. https://doi.org/10.2175/106143017X15131012187971 